\title{
Applications of Low-voltage Ohmic Process Combined with Temperature Control System to Enhance Salting Process of Pork
}

\author{
Geun-Pyo Hong ${ }^{1}$, Ji-Yeon Chun ${ }^{1}$, and Mi-Jung Choi* \\ Department of Molecular Biotechnology, Konkuk University, Seoul 143-701, Korea \\ ${ }^{1}$ Department of Food Science and Biotechnology of Animal Resources, Konkuk University, Seoul 143-701, Korea
}

\begin{abstract}
This study investigated the effects of a low-voltage ohmic heating process $(2.5$ and $3.8 \mathrm{~V} / \mathrm{cm})$ on the thawing characteristics and $\mathrm{NaCl}$ diffusion of pork. The thawing rate of pork was dependent on the applied voltages and brine salinities, and few differences were obtained in pork quality parameters (color, water-holding capacity, and shear force) regarding the different treatments. The $\mathrm{NaCl}$ concentration of pork after ohmic thawing was higher than that following brineimmersion thawing, however, the $\mathrm{NaCl}$ diffusion did not differ from when fresh meat was immersed in brine. For application of the ohmic process in fresh pork, various ohmic pulses were generated in order to prevent the meat from overheating, and the results indicated that the ohmic process was a better way to enhance $\mathrm{NaCl}$ diffusion compared with immersing pork at high temperature. Although the mechanisms involved in $\mathrm{NaCl}$ diffusion at low-voltage electric field strength were unclear, the present study demonstrated that the ohmic process has a potential benefit in the application of meat processing.
\end{abstract}

Key words: ohmic process, temperature, thawing, pork, $\mathrm{NaCl}$ diffusion

\section{Introduction}

The ohmic process has been commercially applied in the food industry as a heating technology. Although this process has associated faradaic and corrosion problems, it recently attracted considerable attention as a new research subject (Stancl and Zitny, 2010). In contrast to other electro-techniques, the ohmic process is easy to control and simple for commercial scale-up. According to Ohm's law $\left(Q=V I=I^{2} R\right)$, resistive heat $Q$ is generated by the passage of an electric current $I$, and the heat is calculated by the relationship between the voltage gradient and electrical conductivity $\left(Q=\Delta V^{2} \sigma\right)$ (Lewis and Jun, 2012). Since electrical conductivity is proportional to temperature, resistive heat generation during the ohmic process increases with increasing mass temperature, resulting in very rapid heating.

The ohmic process is energy efficient and has the advantage of producing a uniform heat distribution inside food items (McKenna et al., 2006). In particular, the

*Corresponding author: Mi-Jung Choi, Department of Molecular Biotechnology, Konkuk University, Seoul 143-701, Korea. Tel: 82-2-450-3048, Fax: 82-2-455-1044, E-mail: choimj@konkuk. ac. $\mathrm{kr}$ energy efficiency of the ohmic process enables the process to inactivate enzymes and microorganisms, including spores (Kaküb et al., 2010; Somavat et al., 2012). Alternatively, resistive heating might be used as a thawing technique. In our previous study, the ohmic process was employed as a meat thawing technique (Hong et al., 2007). Directly passing current to a frozen meat surface provided rapid thawing, and the thawing rate of pork showed an exponential increase with increasing voltage. However, there was strong evidence of lipid oxidation and protein denaturation under the electrode-contact-type ohmic process, whereas the brine-immersion-type ohmic process minimized quality changes compared with a fresh control. Nevertheless, brine immersion $(0.9 \% \mathrm{NaCl})$ manifested some quality changes, such as water-holding capacity and shear force, possibly due to moisture transfer between meat and brine.

Considering the quality of frozen meat, a thawing method that affects the physicochemical properties of meat is inappropriate; nevertheless, mass transfer between meat and brine is inevitable. On the other hand, Kulshrestha and Sastry (2003) postulated that ohmic treatment enhanced mass transfer in the system. From the mass transfer perspective, brine in the ohmic process can be used not only 
as a current conducting medium but also as a meat-salting ingredient, and it can decrease the processing time required by separate thawing and salting processes (Grau et al., 2011). In the present study, therefore, the effects of brine salinity and voltage on the thawing characteristics of pork were estimated, and the $\mathrm{NaCl}$ gain of pork treated by various ohmic processes was explored under a low electric field strength.

\section{Materials and Methods}

\section{Sample preparation}

Pork loin (m. longissimus dorsi) was obtained from a local abattoir $48 \mathrm{~h}$ post mortem. Meat was trimmed of all visible fat and connective tissue, and then, it was cut into rectangular pieces $(3 \times 4 \times 6 \mathrm{~cm})$ from the inner muscle parallel to the fiber direction. A thermocouple probe was inserted into the geometric center of the meat samples. Meat samples were wrapped with plastic film to prevent evaporative losses. Some samples were frozen at $-30^{\circ} \mathrm{C}$ for $24 \mathrm{~h}$, and the others were kept at $4^{\circ} \mathrm{C}$ in a refrigerator. For the ohmic medium, brine solutions with different salinities were prepared by dissolving the desired amount of $\mathrm{NaCl}$ in distilled water $(0-2 \% \mathrm{NaCl}, \mathrm{w} / \mathrm{v})$.

\section{Ohmic device}

A homemade ohmic device, as described in our previous study (Hong et al., 2007), was employed to evaluate the ohmic process (Fig. 1). In brief, the ohmic device was made up of a resistive cell $(500 \mathrm{~mL}$ working volume and $8 \mathrm{~cm}$ distance between electrodes), a temperature recorder (MV 104, Yokogawa Co., Japan), and a power supply

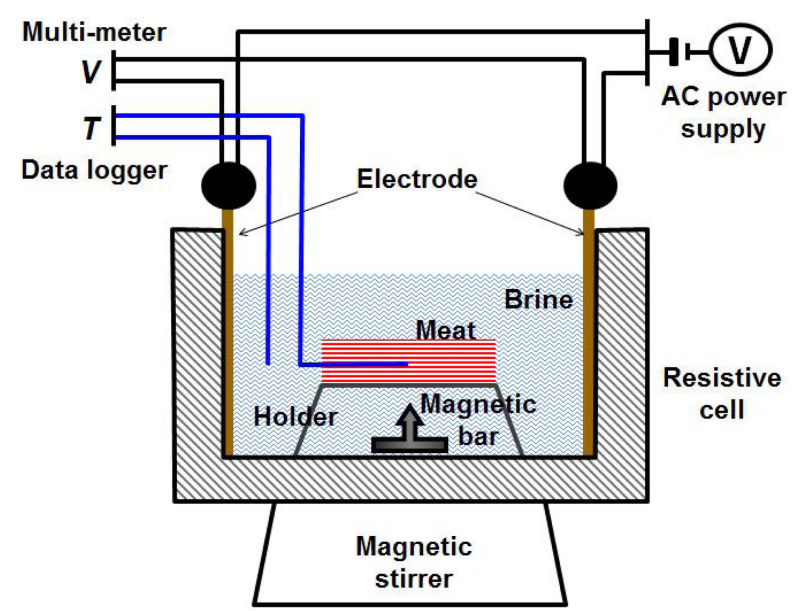

Fig. 1. Schematic diagram of the ohmic apparatus. Resistive cell had a working volume of $500 \mathrm{~mL}$, and the distance between electrodes was $8 \mathrm{~cm}$.
(ACP1010, ACP Power Korea Co. Inc., Korea), and the voltage applied between electrodes was monitored by connecting a multimeter. Brine was stirred during ohmic operation using a low-speed magnetic stirrer $(60 \mathrm{rpm})$. Temperature changes as a function of time during the ohmic process were acquired from the sample core and medium. All ohmic treatments were conducted at a frequency of $60 \mathrm{~Hz}$ and at constant voltages of 20 or $30 \mathrm{~V}$, which corresponded to electric field strengths of 2.5 and $3.8 \mathrm{~V} / \mathrm{cm}$, respectively. All ohmic treatments were conducted in a $4^{\circ} \mathrm{C}$ refrigerator.

\section{Ohmic thawing}

The resistive cell and brines were tempered at $4^{\circ} \mathrm{C}$ overnight. Frozen pork was attached to a sample holder in the resistive cell, and thermocouples were connected to the recorder. Cold brine $(400 \mathrm{~mL})$ was poured into the cell, and pork thawing was initiated by applying the desired voltages $(20$ and $30 \mathrm{~V})$. When the sample core temperature reached $1^{\circ} \mathrm{C}$, the voltage was cut off and the pork was kept at $4^{\circ} \mathrm{C}$ prior to analysis.

\section{Instrumental color}

The pork surface color was monitored using a color reader (CR-10, Konica Minolta Sensing, Inc., Japan) calibrated with a white standard plate $\left(L^{*}=97.83, a^{*}=-0.43\right.$, and $\left.b^{*}=+1.98\right)$. CIE $L^{*}, a^{*}$, and $b^{*}$ values were determined as indicators of lightness, redness, and yellowness, respectively. The sample was kept at ambient conditions for $10 \mathrm{~min}$, and six measurements were performed randomly from the surface of the sample.

\section{Shear force}

The pork sample was vacuum-packed using a poly nylon pouch, thermally treated in a $75^{\circ} \mathrm{C}$ water bath for $20 \mathrm{~min}$, and cooled in ice/water for $15 \mathrm{~min}$. The meat was tempered at ambient conditions for $1 \mathrm{~h}$, and two strips $(1 \mathrm{~cm}$ in diameter and $6 \mathrm{~cm}$ long) subjected to each treatment were cut parallel to the longitudinal orientation of muscle fibers. Meat strips were sheared using a digital gauge (DPS-20, IMADA Co., Japan) at a head speed of $60 \mathrm{~mm} /$ min. Shear force was determined three times for each strip.

\section{Moisture content}

The moisture content of the pork was determined in triplicate by AOAC (1990). Approximately $1 \mathrm{~g}$ of pork was weighed and dried at $105^{\circ} \mathrm{C}$ for $24 \mathrm{~h}$. After drying, the meat was weighed and the moisture content was 
expressed as a percentage of initial weight.

\section{$\mathrm{NaCl}$ Diffusion of fresh and frozen pork}

In all cases, $2 \%(\mathrm{w} / \mathrm{v}) \mathrm{NaCl}$ solution was used as brine. To compare the effect of meat state (fresh versus frozen) on $\mathrm{NaCl}$ diffusion (experiment 1), frozen pork was immersed into cold brine until the meat core temperature reached $1^{\circ} \mathrm{C}$, and the total thawing time was estimated. To compare pork states, an unfrozen pork sample was immersed into cold brine for the same length of time as the frozen one. Ohmic thawing at $2.5 \mathrm{~V} / \mathrm{cm}$ was conducted following the procedure described above. All procedures were carried out in a $4^{\circ} \mathrm{C}$ refrigerator.

In experiment 2 , the effect of temperature on $\mathrm{NaCl}$ diffusion was explored. Ohmic thawing (OT, $2.5 \mathrm{~V} / \mathrm{cm}$ ) was conducted using the same method as in experiment 1 , and the total thawing time was determined. Fresh pork was immersed in cold brine $\left(\mathrm{LT}, 4^{\circ} \mathrm{C}\right)$ and tempered brine $\left(\mathrm{HT}, 35^{\circ} \mathrm{C}\right)$, respectively. Because the ohmic treatment of fresh pork induced an excessive heating inside the sample that could not be controlled over the overall experiment, ohmic treatment was repeated at $200 \mathrm{~s}$ intervals (PO). All treatments were conducted in a $4^{\circ} \mathrm{C}$ refrigerator for the same length of time as OT treatment, with the exception of HT treatment, which was performed under ambient conditions to prevent cooling.

\section{Comparison of ohmic pulses}

Ohmic pulses were generated by controlling the ohmic power based on the meat core temperature. Fresh pork in cold brine $(2 \% \mathrm{NaCl}, \mathrm{w} / \mathrm{v})$ was subjected to ohmic treatment $(2.5 \mathrm{~V} / \mathrm{cm})$ until the core temperature reached $27^{\circ} \mathrm{C}$, and then, the ohmic power was cut off. To generate various pulses, meat was cooled down to 19 (O1), 23 (O2), and $25^{\circ} \mathrm{C}(\mathrm{O} 3)$, and then ohmic power was applied. This procedure was repeated for $3.5 \mathrm{~h}$ at $4^{\circ} \mathrm{C}$. As a non-ohmic treated control, a pork sample was immersed in $4^{\circ} \mathrm{C}$ cold brine for $3.5 \mathrm{~h}$ (LC), while another pork sample was subjected to a tempered brine maintained at $28^{\circ} \mathrm{C}$ in a water bath for $3.5 \mathrm{~h}(\mathrm{HC})$.

\section{$\mathrm{NaCl}$ concentration}

The $\mathrm{NaCl}$ concentration of pork was determined by Mohr's method (Belcher et al., 1957). Approximately $5 \mathrm{~g}$ of pork was homogenized with $80 \mathrm{~mL}$ of hot distilled water at 17,000 rpm for $2 \mathrm{~min}$ using a homogenizer and stirred for $30 \mathrm{~min}$. Distilled water was added to the homogenate up to a final volume of $200 \mathrm{~mL}$. The mixture was filtered through Whatman No. 5 filter paper. A $20-\mathrm{mL}$ ali- quot of filtrate was reacted with $1 \mathrm{~mL}$ of $10 \% \mathrm{~K}_{2} \mathrm{CrO}_{4}$, and $\mathrm{Cl}$ concentration was determined by titration with 0.1 $\mathrm{N} \mathrm{AgNO}$, until the sample color shifted to dark brown. The $\mathrm{NaCl}$ concentration was calculated as:

$$
\operatorname{NaCl}(\%)=\frac{0.005845 *(A-B) * f}{W t_{\text {Meat }}} \times 100
$$

where $A$ and $B$ indicate the volume of titrated $\mathrm{AgNO}_{3}$ of the sample and blank, respectively, and $f$ and $W t_{\text {Meat }}$ are the dilution factor and weight of the meat, respectively.

\section{Statistical analysis}

A completely randomized block design was employed to analyze the results. Data were analyzed by the general linear model procedure using the SAS program (ver. 9.1). Analysis of variance (ANOVA) was performed, and the means were separated by Fisher's Least Significant Difference (LSD) test when the main effect was significant $(p<0.05)$.

\section{Results and Discussion}

\section{Thawing profiles of pork}

The total thawing time of pork was affected both by brine salinity and by applied voltage (Fig. 2). At an electric field strength of $2.5 \mathrm{~V} / \mathrm{cm}$, the overall thawing time of pork was about 77 min for a distilled water medium (Fig. 2A), which was similar to $74 \mathrm{~min}$ for equivalent pork thawed at $3.8 \mathrm{~V} / \mathrm{cm}$ (Fig. 2B). At both electric field strengths, the temperature of the medium showed a minor increase throughout the operations $\left(\Delta T<2{ }^{\circ} \mathrm{C}\right)$. A minor temperature increase in the medium indicated that distilled water had a lower electrical conductivity compared to brine (Darvishi et al., 2011; Hayashi, 2004). On the other hand, a saline medium caused rapid meat thawing, and the total thawing time decreased to under $1 \mathrm{~h}(\sim 52 \mathrm{~min})$ for $0.2 \%$ $\mathrm{NaCl}$ and approached about $30 \mathrm{~min}$ for $2 \% \mathrm{NaCl}$ (Fig. 2A). It was believed that changes in the thawing time of frozen pork resulting from the ohmic process were not due to ohmic heat generation inside the pork but due to heat transfer between the medium and pork, as shown by the linear relationship between salinity and temperature of medium (Fig. 2C). The results showed that, as is commonly recognized, electrical conductivity is of importance for heat generation within the food matrix. Electrolytes, such as $\mathrm{NaCl}$, increased the electrical conductivity of medium, which in turn promoted high electrical resistance, accelerating the overall thawing process of pork. Although ice with salt had higher electrical conductivity 

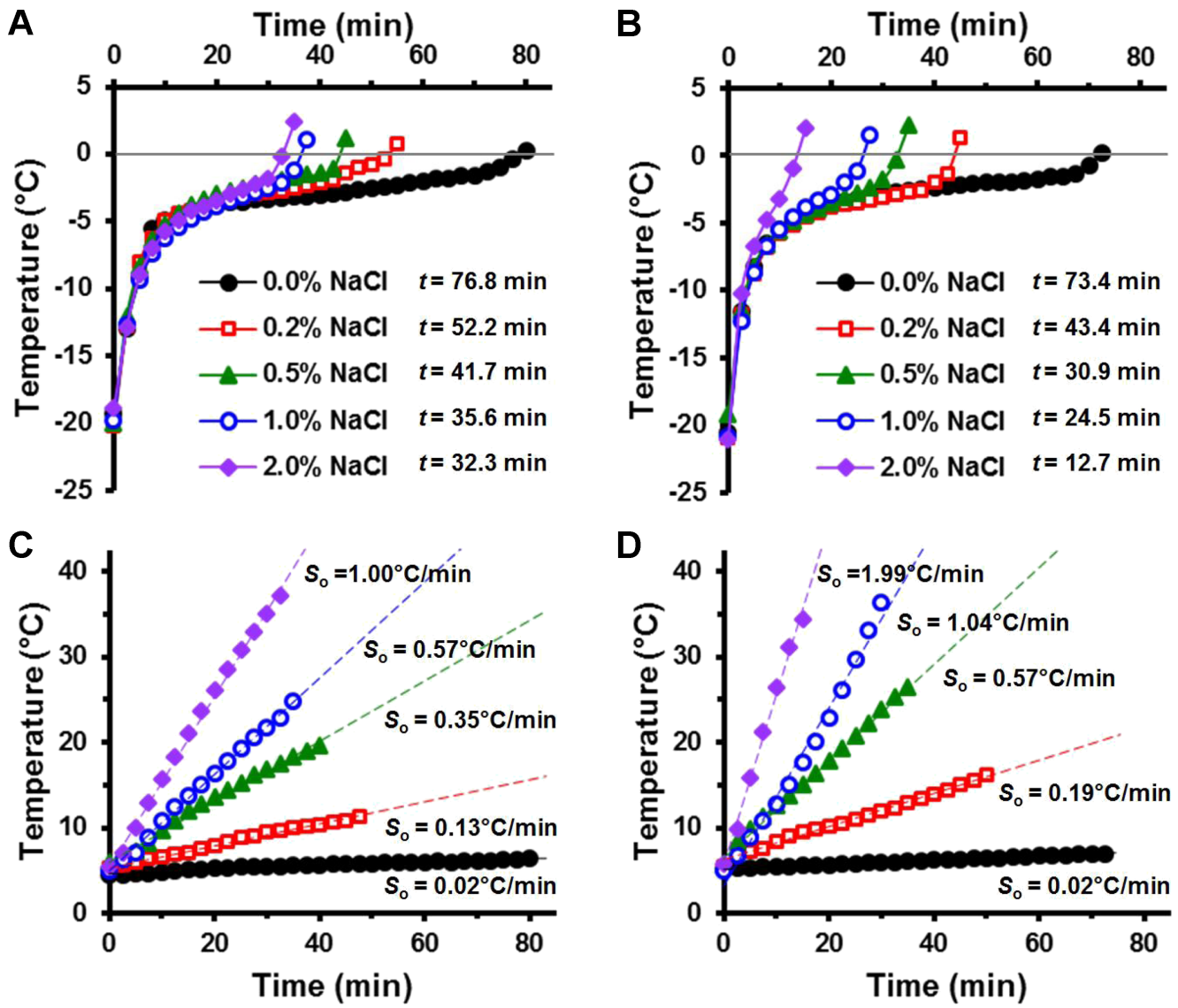

Fig. 2. Thawing profiles of pork thawed by the ohmic system (A, B) and changes in temperature of the medium (C, D) at electric field strengths of $2.5 \mathrm{~V} / \mathrm{cm}(\mathbf{A}, \mathbf{C})$ and $3.8 \mathrm{~V} / \mathrm{cm}(\mathbf{B}, \mathbf{D}) . t$ and $S_{\mathrm{o}}$ indicate total thawing time of pork and the slope of the timetemperature relationship in the medium, respectively.

than pure ice, the conductivity of ice was considerably lower than that of water, thereby limiting ohmic heat generation inside pork compared to the medium (Stillman and Grimm, 2008). On the other hand, heat generation of the medium dominated for $3.8 \mathrm{~V} / \mathrm{cm}$ ohmic processing, where the extent of temperature increase in the medium was almost twice that at $2.5 \mathrm{~V} / \mathrm{cm}$ (Fig. 2D). As a result, pork treated at $3.8 \mathrm{~V} / \mathrm{cm}$ in $2 \% \mathrm{NaCl}$ medium had a total thawing time of about $13 \mathrm{~min}$. Consequently, the results indicated that the overall thawing process of frozen pork could be reduced by increasing the voltage and salinity of the medium. Although high heat generation by the medium could be inappropriate for meat thawing from the food hygiene viewpoint, the overall reduction in thawing time might eliminate the potential restriction imposed by a high processing temperature.

\section{Quality of frozen pork thawed by ohmic process}

The quality characteristics of frozen pork thawed by ohmic processing were compared with those of a fresh control (Table 1). Voltage variations did not affect the $L^{*}$ value of pork, with the exception of pork treated in $2 \%$ brine, where pork thawed at $3.8 \mathrm{~V} / \mathrm{cm}$ was lighter than that thawed at $2.5 \mathrm{~V}(p<0.05)$. The brine salinity affected the lightness of pork, as pork treated at $2.5 \mathrm{~V} / \mathrm{cm}$ had a different lightness for $0 \%$ and $2 \%$ brine, whereas all pork treated at $3.8 \mathrm{~V} / \mathrm{cm}$ in brine showed a lower $L^{*}$ value compared with that in $0 \%$ brine $(p<0.05)$. Neither voltage nor brine salinity influenced the $a^{*}$ value of pork, although increasing brine salinity tended to increase the $a^{*}$ value of pork. The voltage variations did not affect the $b^{*}$ value of pork, while the $b^{*}$ value of pork tended to increase with increasing brine salinity $(p<0.05)$. Increasing brine salinity up to $0.5 \% \mathrm{NaCl}$ increased the shear value of pork treated at $2.5 \mathrm{~V} / \mathrm{cm}$, and the highest shear value was obtained at higher than $1 \% \mathrm{NaCl}(p<0.05)$. The patterns in shear value of pork treated at $3.8 \mathrm{~V} / \mathrm{cm}$ were similar to those at $2.5 \mathrm{~V} / \mathrm{cm}$, while the $2 \%$ brine treatment had a lower shear value than that of the $1 \%$ treatment $(p<0.05)$. The moisture content of ohmic treated pork tended to decrease with increasing salinity, and the moisture content of pork treated in $2 \%$ brine was lower than that in $0 \%$ brine $(p<0.05)$. However, there were no differences in moisture content among various brine treatments at 3.8 
Table 1. Quality parameters of pork thawed by the ohmic process under various brines

\begin{tabular}{|c|c|c|c|c|c|c|}
\hline \multirow{2}{*}{\multicolumn{2}{|c|}{ EFS $^{1)}$}} & \multicolumn{5}{|c|}{ Brine $\mathrm{NaCl}(\%)$} \\
\hline & & 0 & 0.2 & 0.5 & 1 & 2 \\
\hline \multirow{2}{*}{ CIE L* } & $2.5 \mathrm{~V} / \mathrm{cm}$ & $51.7 \pm 1.64^{\mathrm{a}, 2)}$ & $50.5 \pm 1.08^{\mathrm{a}}$ & $50.8 \pm 2.81^{\mathrm{a}}$ & $49.7 \pm 1.50^{\mathrm{ab}}$ & $46.5 \pm 1.51^{\mathrm{b}, \mathrm{y}}$ \\
\hline & $3.8 \mathrm{~V} / \mathrm{cm}$ & $52.9 \pm 0.21^{\mathrm{a}}$ & $49.2 \pm 0.91^{b}$ & $50.5 \pm 1.31^{b}$ & $49.1 \pm 1.66^{\mathrm{b}}$ & $49.5 \pm 0.80^{\mathrm{b}, \mathrm{x}}$ \\
\hline \multirow{2}{*}{ CIE $a^{*}$} & $2.5 \mathrm{~V} / \mathrm{cm}$ & $4.53 \pm 0.35$ & $4.53 \pm 0.31$ & $4.87 \pm 0.42$ & $5.01 \pm 0.53$ & $5.00 \pm 0.30$ \\
\hline & $3.8 \mathrm{~V} / \mathrm{cm}$ & $4.37 \pm 0.31$ & $4.37 \pm 0.32$ & $4.50 \pm 0.36$ & $4.67 \pm 0.21$ & $4.63 \pm 0.21$ \\
\hline \multirow{2}{*}{ CIE b* } & $2.5 \mathrm{~V} / \mathrm{cm}$ & $4.67 \pm 0.35^{b}$ & $5.03 \pm 0.21^{\mathrm{ab}}$ & $5.20 \pm 0.46^{\mathrm{ab}}$ & $5.20 \pm 0.26^{\mathrm{ab}}$ & $5.37 \pm 0.25^{\mathrm{a}}$ \\
\hline & $3.8 \mathrm{~V} / \mathrm{cm}$ & $4.33 \pm 0.12^{\mathrm{b}}$ & $4.83 \pm 0.15^{\mathrm{a}}$ & $5.13 \pm 0.40^{\mathrm{a}}$ & $5.17 \pm 0.25^{\mathrm{a}}$ & $5.17 \pm 0.21^{\mathrm{a}}$ \\
\hline \multirow{2}{*}{ Shear force $(\mathrm{N})$} & $2.5 \mathrm{~V} / \mathrm{cm}$ & $7.40 \pm 0.44^{\mathrm{c}}$ & $7.80 \pm 0.43^{b c}$ & $8.79 \pm 1.27^{\mathrm{b}}$ & $9.94 \pm 0.53^{\mathrm{a}}$ & $9.88 \pm 0.44^{\mathrm{a}, \mathrm{x}}$ \\
\hline & $3.8 \mathrm{~V} / \mathrm{cm}$ & $8.24 \pm 0.78^{b}$ & $8.14 \pm 0.17^{b}$ & $9.72 \pm 0.47^{\mathrm{a}}$ & $9.86 \pm 0.23^{\mathrm{a}}$ & $8.52 \pm 0.67^{\mathrm{b}, \mathrm{y}}$ \\
\hline \multirow{2}{*}{ Moisture (\%) } & $2.5 \mathrm{~V} / \mathrm{cm}$ & $86.2 \pm 1.57^{\mathrm{a}}$ & $85.4 \pm 1.86^{\mathrm{a}}$ & $85.0 \pm 1.53^{\mathrm{ab}}$ & $83.3 \pm 2.52^{\mathrm{ab}}$ & $82.0 \pm 1.52^{b}$ \\
\hline & $3.8 \mathrm{~V} / \mathrm{cm}$ & $85.8 \pm 2.61$ & $83.4 \pm 1.68$ & $83.7 \pm 1.49$ & $83.2 \pm 1.04$ & $84.5 \pm 2.11$ \\
\hline
\end{tabular}

${ }^{1)}$ Electric field strength

${ }^{2)}$ Mean \pm standard deviation from triplicate determinations $(n=3)$

${ }^{a, b}$ Means with different superscript within same column are significantly different $(p<0.05)$.

${ }^{\mathrm{x}, \mathrm{y}}$ Means with different superscript within same row are significantly different $(p<0.05)$.

$\mathrm{V} / \mathrm{cm}$.

In general, brine-immersion-type ohmic processing as a meat thawing technique did not change the meat color after treatment, which was also confirmed in our previous work (Hong et al., 2007). Nevertheless, migration of $\mathrm{NaCl}$ from brine to pork surface was likely manifested as a slight difference of pork qualities based on salinity. Since pork meat contains about $0.18 \% \mathrm{NaCl}$, osmotic dehydration or hydration might occur depending on the brine salinity. For a $0 \%$ brine treatment, moisture hydration on the meat surface would result in a high moisture content and a lighter appearance, as well as reduced toughness of the pork meat (Boles and Shand, 2001; Shahidi et al., 1992). On the other hand, at high salinity, particularly at $2 \% \mathrm{NaCl}$ concentration, moisture and $\mathrm{NaCl}$ diffusion would facilitate moisture loss from the meat surface, resulting in a high shear score value and a darker appearance. However, an electric field strength of $3.8 \mathrm{~V} /$ $\mathrm{cm}$ in $2 \%$ brine medium caused rapid thawing $(\sim 12.7$ min) and possibly minimized mass transfer during the thawing process. The results indicated that application of ohmic thawing with high salinity and ohmic power was an appropriate thawing technique for frozen meat. Otherwise, mass transfer could be enhanced by high salinity $(2 \% \mathrm{NaCl})$ under a low electric field strength $(2.5 \mathrm{~V} / \mathrm{cm})$, which provided a possibility of reducing the processing time required in commercial processed meat production.

\section{$\mathrm{NaCl}$ diffusion of fresh and frozen pork}

Pork in brine inevitably experiences water and $\mathrm{NaCl}$ diffusion between meat and brine. In other words, $\mathrm{NaCl}$ diffusion into meat during thawing can be used as part of the meat-salting process, because it enables the overall processing time for salting the processed meat products to be reduced. As a preliminary study, the $\mathrm{NaCl}$ content of pork thawed by an ohmic system $(2.5 \mathrm{~V} / \mathrm{cm}$ in $2 \%$ brine $)$ was compared with that of $2 \%$ brine immersion thawing (non-ohmic treatment) and immersion of fresh meat (Table 2). As expected, frozen pork thawed by brine immersion $(2 \% \mathrm{NaCl})$ for $1 \mathrm{~h}$ showed less integrity of $\mathrm{NaCl}$ gain and

Table 2. Descriptions of various pork treatments and NaCl concentration after treatment

\begin{tabular}{|c|c|c|c|c|c|c|}
\hline Treatme & ent descriptions & Pork state & Time (min) & Temperature $\left({ }^{\circ} \mathrm{C}\right)$ & Ohmic treatment & $\mathrm{NaCl}$ gain $(\%)^{1)}$ \\
\hline \multirow{3}{*}{$\begin{array}{c}\text { Experiment } \\
1\end{array}$} & Immersion & Fresh & 60 & 4 & - & $0.46 \pm 0.02^{\mathrm{a}}$ \\
\hline & Immersion thawing & Frozen & 60 & 4 & - & $0.29 \pm 0.03^{\mathrm{b}}$ \\
\hline & Ohmic thawing & Frozen & 34 & 4 & $20 \mathrm{~V}$ & $0.48 \pm 0.04^{\mathrm{a}}$ \\
\hline \multirow{4}{*}{$\begin{array}{c}\text { Experiment } \\
2\end{array}$} & Immersion (LT) & Fresh & 38 & 4 & - & $0.38 \pm 0.03^{\mathrm{d}}$ \\
\hline & Ohmic thawing (OT) & Frozen & 38 & $4-24$ & $20 \mathrm{~V}$ & $0.50 \pm 0.02^{\mathrm{c}}$ \\
\hline & Immersion (HT) & Fresh & 38 & $>23$ & - & $0.57 \pm 0.01^{\mathrm{b}}$ \\
\hline & Ohmic pulse (PO) & Fresh & 38 & $4-21$ & 20 V Pulse ${ }^{2)}$ & $0.64 \pm 0.01^{\mathrm{a}}$ \\
\hline
\end{tabular}

${ }^{1)}$ Mean \pm SD from triplicate determinations $(n=3)$. Means with different superscript within same experiment are significantly different $(p<0.05)$.

${ }^{2)}$ Ohmic pulse was provided by cut off the ohmic power at every $200 \mathrm{~s}$ gaps. 
showed $0.29 \% \mathrm{NaCl}$ concentration, which was obviously lower than $0.46 \%$ for the fresh counterpart $(p<0.05)$. Meanwhile, pork thawed by ohmic processing showed $0.48 \% \mathrm{NaCl}$ concentration, which did not differ from that of fresh pork. Even though the period of immersion for the ohmic treatment was short (35 min), the lack of a difference in $\mathrm{NaCl}$ concentration for pork treated by the ohmic processing and fresh pork reflected the potential advantages of the ohmic process in mass transfer kinetics. It was recognized that ohmic heating improved the diffusion kinetics of foods, as the increased temperature of the conductor (sample food) promoted swelling and plasticizing of cell membranes (Allali et al., 2010). Considering the temperature dependency of mass transfer, it makes sense that the generation of high resistive heat in ohmic processing increased $\mathrm{NaCl}$ diffusion into meat compared with cold brine immersion treatments $\left(4^{\circ} \mathrm{C}\right)$. However, it was uncertain whether the tissue membrane of pork might be influenced by a relatively low electric field strength $(2.5 \mathrm{~V} / \mathrm{cm})$ and final medium temperature $\left(<40^{\circ} \mathrm{C}\right)$. Although there was no literature comparable to this study, Lebovka et al. (2005) reported that ohmic heating at $20 \mathrm{~V} / \mathrm{cm}$ without exceeding $50^{\circ} \mathrm{C}$ caused great tissue damage in apples (electroporation). Ultimately, the factors involved in $\mathrm{NaCl}$ diffusion in ohmic processed pork can be classified according to the temperature and extent of membrane damage of pork meat. To explore which factor is of importance in $\mathrm{NaCl}$ diffusion, pulsed ohmic treatment was attempted and compared with high-temperature (HT) treatment (Fig. 3). The samples for all treatments were immersed in brine for $38 \mathrm{~min}$ to reflect the total thawing time required for ohmic thawing (OT) treatment. Fresh pork immersed in cold brine (LT) showed the lowest $\mathrm{NaCl}$ gain among

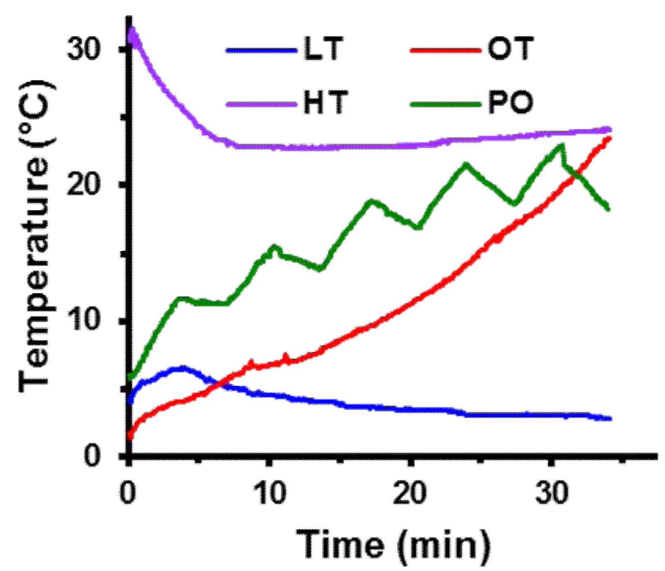

Fig. 3. Temperature profiles of brine during various treatments. LT, low temperature control; OT, ohmic thawing; HT, high-temperature control; PO, pulsed ohmic treatment. the treatments $(p<0.05)$, which would be evidenced by a short immersion time compared with $1 \mathrm{~h}$ as described above. Meanwhile, OT treatments showed a $\mathrm{NaCl}$ gain that was lower than that of fresh pork immersed at $>24^{\circ} \mathrm{C}$ (HT) $(p<0.05)$. Consequently, ohmic thawing showed a potential advantage in $\mathrm{NaCl}$ diffusion during thawing; however, the efficiency was not as high as that for fresh pork immersed at a higher temperature. On the other hand, fresh pork subjected to ohmic pulses (PO) exhibited the highest $\mathrm{NaCl}$ gain $(p<0.05)$, even though the overall temperature of the medium was lower than that in the case of HT treatment. The results demonstrated that the ohmic process improved the mass transfer reaction of the food matrix without any dependence on processing temperature.

\section{Effect of various pulses on $\mathrm{NaCl}$ diffusion}

Ohmic processing obviously improved $\mathrm{NaCl}$ diffusion in pork meat. For commercial application, however, it was necessary to increase the overall ohmic processing time to achieve a sufficiently high $\mathrm{NaCl}$ concentration in the meat. Unlike frozen pork, a high resistive heat was generated inside fresh pork during ohmic processing, which manifested as undesirable overheating of the meat sample. Therefore, pulsed ohmic treatment was applied to prevent the sample overheating. In this investigation, ohmic pulses were applied based on the temperature inside the pork sample. Pork meat in $2 \%$ brine was treated by the ohmic process until the core temperature of the meat reached a maximum at $27^{\circ} \mathrm{C}$, and then, the ohmic power was cut off until the core temperature decreased to 19 $(\mathrm{O} 1), 23(\mathrm{O} 2)$, and $25^{\circ} \mathrm{C}(\mathrm{O} 3)$ to provide variations of pulses (Fig. 4A). After $3.5 \mathrm{~h}$ of cold brine immersion $\left(\mathrm{LC}, 4^{\circ} \mathrm{C}\right)$, there was a $0.58 \% \mathrm{NaCl}$ gain in pork, which was lower than $0.77 \%$ for the high temperature control $\left(\mathrm{HC}, 27^{\circ} \mathrm{C}\right)(p<0.05)$. The $\mathrm{NaCl}$ concentration produced by ohmic treatments depended on the pulses applied and showed that $\mathrm{O} 1$ and $\mathrm{O} 2$ treatments had higher $\mathrm{NaCl}$ gain than $\mathrm{HC}(p<0.05)$, but the $\mathrm{NaCl}$ concentration of the $\mathrm{O} 3$ treatment did not differ from HC (Fig. 4B). Despite the highest mean temperature $\left(\sim 25^{\circ} \mathrm{C}\right)$ of $\mathrm{O} 3$ (compared with O1 $\left(\sim 22^{\circ} \mathrm{C}\right)$ or $\mathrm{O} 2\left(\sim 23^{\circ} \mathrm{C}\right)$ treatments), a smaller $\mathrm{NaCl}$ gain for $\mathrm{O} 3$ among the ohmic treatments reflected that the temperature-dependent mass transfer reaction did not fully account for the $\mathrm{NaCl}$ gain under ohmic processing. Although the mechanism and relationship between ohmic pulses and $\mathrm{NaCl}$ diffusion warrants further exploration, the present study indicated that extension of processing time, thereby enhancing $\mathrm{NaCl}$ diffusion in pork, could be 

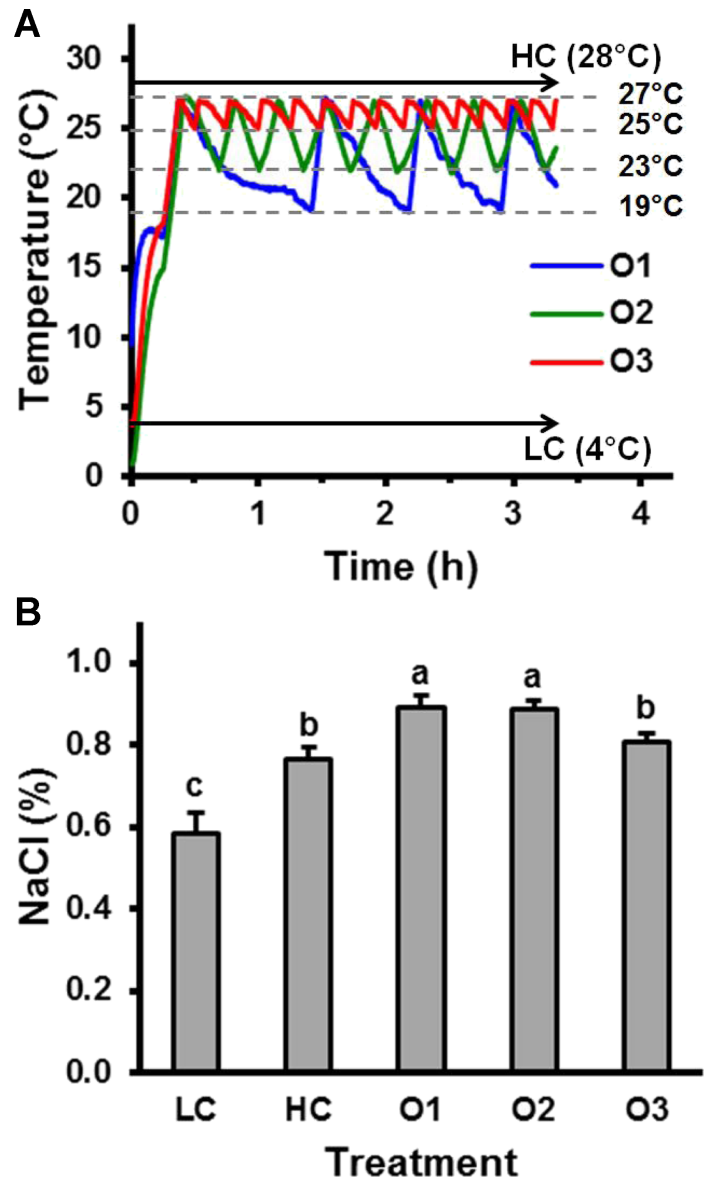

Fig. 4. Temperature profiles of pork treated with various ohmic pulses (A) and $\mathrm{NaCl}$ concentration after $3.5 \mathrm{~h}$ treatment (B). LC and $\mathrm{HC}$ indicate low and high temperature controls (non-ohmic treatment), respectively. Vertical bars indicate standard deviations. Means with different letters are significantly different $(p<0.05)$.

achieved by low-voltage ohmic pulse treatment, and the higher the brine salinity, the higher might be the $\mathrm{NaCl}$ concentration of the pork.

\section{Conclusion}

The salinity of the medium in ohmic processing was an important factor in reducing the overall thawing time of pork. However, $\mathrm{NaCl}$ in the brine transferred into the pork meat, which limited the application of ohmic processing as a meat thawing technique. A useful application of the ohmic process was that the $\mathrm{NaCl}$ gain during ohmic treatment could be regarded as an advantage in the meat-salting process, if the individual thawing and salting processes of meat were combined. Although the mechanisms involved in the mass transfer phenomenon during ohmic processing were unclear, the present study demonstrated that low-voltage ohmic processing enhanced $\mathrm{NaCl}$ diffusion from brine into meat, which could be regulated by variations of ohmic pulses.

\section{References}

1. Allali, H., Marchal, L., and Vorobiev, E. (2010) Blanching of strawberries by ohmic heating: Effects on the kinetics of mass transfer during osmotic dehydration. Food Bioprocess Technol. 3, 406-414.

2. AOAC (1990). Official methods of analysis of AOAC International. (15th ed.). Association of Official Analytical Chemists, Washington, DC.

3. Belcher, R., Macdonald, A. M. G., and Parry, E. (1957) On mohr's method for the determination of chlorides. Anal. Chim. Acta 16, 524-529.

4. Boles, J. A. and Shand, P. J. (2001) Meat cut and injection level affects the tenderness and cook yield of processed roast beef. Meat Sci. 59, 259-265.

5. Darvishi, H., Hosainpour, A., Nargesi, F., Khoshtaghaza, M. H., and Torang, H. (2011) Ohmic processing: Temperature dependent electrical conductivities of lemon juice. Mod. Appl. Sci. 5, 209-216.

6. Grau, R., Albarracin, W., Pérez, M. T., Antequera, T., and Barat, J. M. (2011) Use of simultaneous brine thawing/salting in dry-cured Iberian ham production. J. Food Eng. 104, 316-321.

7. Hayashi, M. (2004) Temperature-electrical conductivity relation of water for environmental monitoring and geophysical data inversion. Environ. Monit. Assess. 96, 119-128.

8. Hong, G. P., Min, S. G., Ko, S. H., Shim, K. B., Seo, E. J., and Choi, M. J. (2007) Effects of brine immersion and electrode contact type low voltage ohmic thawing on the physic-chemical properties of pork meat. Korean J. Food Sci. Anim. Resour. 27, 416-423.

9. Kaküb, A., Bryjak, J., Wüjtowicz, H., Illeová, V., Annus, J., and Polakoviè, M. (2010) Inactivation kinetics of food enzymes during ohmic heating. Food Chem. 123, 369-376.

10. Kulshrestha, S. and Sastry, S. (2003) Frequency and voltage effects on enhanced diffusion during moderate electric field (MEF) treatment. Innov. Food Sci. Emerging Technol. 4, 189-194.

11. Lebovka, N., Ghnimi, P. S., and Vorobiev, E. (2005) Does electroporation occur during the ohmic heating of food? $J$. Food Sci. 70, 308-311.

12. Lewis, M. J. and Jun, S. (2012) Thermal processing. In J. G. Brennan and A. S. Grandison (eds.), Food processing handbook (2nd ed), Weinheim, Wiley-VCH, pp. 31-75.

13. MckKenna, B. M., Lyng, J., Brunton, N., and Shirsat, N. (2006) Advances in radio frequency and ohmic heating of meats. J. Food Eng. 77, 215-229.

14. Shahidi, F., Synowiecki, J., and Onodenalore, A. C. (1992). Effects of aqueous washings on colour and nutrient quality of mechanically deboned chicken meat. Meat Sci. 32, 289297.

15. Somavat, R., Mohamed, H. M. H., Chung, Y. K., Yousef, A. 
E., and Sastry, S. K. (2012) Accelerated inactivation of Geobacillus stearothermophilus spores by ohmic heating. $J$. Food Eng. 108, 69-76.

16. Stancl, J. and Zitny, R. (2010). Milk fouling at direct ohmic heating. J. Food Eng. 99, 437-444.

17. Stillman, D. E. and Grimm, R. E. (2008) Electrical properties of ice and implications for solar system exploration. In proceedings of 39th Lunar and Planetary Science Conference, March 10-14, League City, TX.

(Received 2012.3.13/Accepted 2012.5.31) 